\title{
Interesting Images \\ Seahorse Predation by Octopuses in the Caribbean and the West Pacific
}

\author{
Ellen Muller ${ }^{1}$, David Harasti ${ }^{2}$ (D) and Bert W. Hoeksema ${ }^{3,4,5, *(\mathbb{D})}$ \\ 1 Kaya Platina 3, Nawati, Bonaire, Caribbean Netherlands; imagine@imaginebonaire.com \\ 2 Fisheries Research, NSW Department of Primary Industries, Taylors Beach, NSW 2316, Australia; \\ david.harasti@dpi.nsw.gov.au \\ 3 Taxonomy, Systematics and Geodiversity Group, Naturalis Biodiversity Center, P.O. Box 9517, \\ 2300 RA Leiden, The Netherlands \\ 4 Groningen Institute for Evolutionary Life Sciences, University of Groningen, P.O. Box 11103, \\ 9700 CC Groningen, The Netherlands \\ 5 Institute of Biology Leiden, Leiden University, P.O. Box 9505, 2300 RA Leiden, The Netherlands \\ * Correspondence: bert.hoeksema@naturalis.nl
}

check for updates

Citation: Muller, E.; Harasti, D.; Hoeksema, B.W. Seahorse Predation by Octopuses in the Caribbean and the West Pacific. Diversity 2022, 14, 125. https://doi.org/10.3390/ d14020125

Academic Editors: Vitor H. Paiva and Michael Wink

Received: 22 December 2021

Accepted: 2 February 2022

Published: 10 February 2022

Publisher's Note: MDPI stays neutral with regard to jurisdictional claims in published maps and institutional affiliations.

Copyright: (C) 2022 by the authors. Licensee MDPI, Basel, Switzerland. This article is an open access article distributed under the terms and conditions of the Creative Commons Attribution (CC BY) license (https:// creativecommons.org/licenses/by/ $4.0 /)$.

\begin{abstract}
There is much documentation about seahorses (Hippocampus spp.) being threatened by habitat degradation and overfishing, but relatively few published studies mention their natural predators. The present study documents three cases in which seahorses are being caught by octopuses. In one case, the seahorse was partly consumed. These observations made at Bonaire (Caribbean Netherlands) and New South Wales (Australia) suggest that predation on seahorses by octopuses may be more widespread and common than previously thought.
\end{abstract}

Keywords: predator; prey; Hippocampus; Octopus; Bonaire; New South Wales

Several studies have been published about how seahorses (Hippocampus spp.) are threatened by overfishing for the traditional medicine market [1-3] and the international aquarium industry [4]. This has resulted in their protection under CITES (Convention for the International Trade in Endangered Species of Wild Fauna and Flora), as of 2002 [5,6]. In comparison, much less is known about the natural enemies of seahorses and their impact on Hippocampus populations. Examples of animals preying on adult seahorses are crustaceans, fishes, sea turtles, water birds, dolphins, and cephalopods [7-12]. Large, adult seahorses are expected to have few predators because of their camouflage and protective armour, consisting of bony plates and spines [12,13], but those consuming juvenile seahorses are probably more diverse, involving various piscivorous fish and planktivorous organisms [12].

Seahorse predation by cephalopods is not well documented; for instance, it is not mentioned in an overview of seahorse predators in a review by Foster and Vincent [13]. Octopuses as seahorse predators have so far only been reported from Portugal [7] and New South Wales, Australia [8]. These cephalopods are well known to be voracious predators, especially of molluscs and crustaceans [14,15], but also of slow-moving fishes such as scorpionfish and lionfish, which use venom as a defence weapon [16-18]. Owing to their upright position and use of camouflage, seahorses are also not expected to rely much on swimming as a means to escape from predation. Considering that octopuses can even break the shells of molluscs and the carapaces of crustaceans, it is not surprising that they are able to consume seahorses, whose protection by bony plates may turn out to be ineffective. In the present report, we present photographic evidence of attacks on seahorse species by octopuses.

The first case concerns a longsnout seahorse (Hippocampus reidi) that was captured and killed by an octopus at Bonaire (Southern Caribbean) on 11 December 2014 (Figure 1). This predator used to be named Octopus vulgaris locally, but is presently known as O. insularis [19]. 
This observation was made during a recreational late-afternoon dive at the airport fuel pier of Bonaire $\left(12^{\circ} 08^{\prime} 03^{\prime \prime} \mathrm{N} 68^{\circ} 16^{\prime} 53^{\prime \prime} \mathrm{W}\right)$, when visibility was poor due to wave action. The seahorse, which had been observed at 7-8 $\mathrm{m}$ depth over a period of many months, was spotted at the start of the dive but was no longer visible at the end of the dive, less than an hour later. It was found back at $4 \mathrm{~m}$ depth in the tight grasp of the octopus, which resided underneath a sea lettuce coral, Helioseris cucullata. The seahorse could not free itself from the grip of its predator (Figure 1a,b) and appeared to be stunned or dead (Figure 1c). It was never seen again during consecutive dives. Hippocampus reidi is a common and widespread species in the West Atlantic and Caribbean Sea, which is considered to be Near-Threatened (NT) by the IUCN Red List [4].
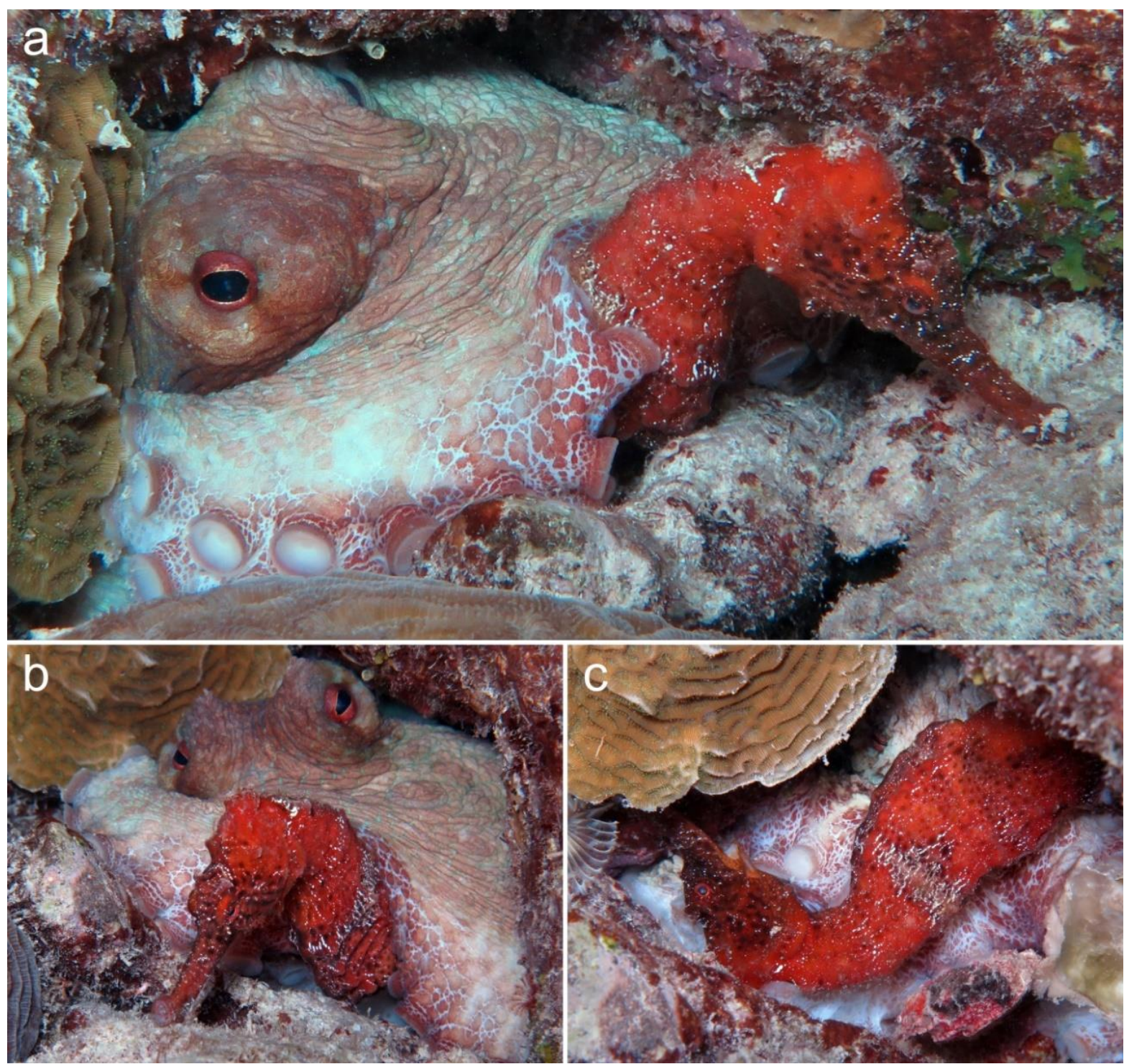

Figure 1. A red longsnout seahorse (Hippocampus reidi) killed by a common octopus (Octopus vulgaris) at Bonaire, Southern Caribbean. The octopus is partly hiding underneath a sunray lettuce coral, Helioseris cucullata. (a,b) The seahorse in the grip of the octopus. (c) The seahorse is stunned or dead. Photo credit: Ellen Muller.

The second case is an individual of Hippocampus whitei partly consumed by a Sydney octopus (Octopus tetricus) at the Pipeline dive site [8] in Nelson Bay of Port Stephens (New South Wales, Australia), $32^{\circ} 43^{\prime} 04^{\prime \prime}$ S $152^{\circ} 08^{\prime} 28^{\prime \prime}$ E, on 13 June 2009 (Figure 2). During a routine dive for the scientific monitoring of the $H$. whitei population here [8], the octopus 
was found with the dead seahorse lying in front of its hiding place, a discarded glass jar (video footage in Supplementary Materials). The tail part of the prey was visible at first (Figure 2a) but disappeared later on (Figure 2b). It is unknown what happened to the head after the dive was over. The seahorse was tagged in 2007 using elastomer (Figure 2) and obviously had escaped predation for some time. It cannot entirely be ruled out that the seahorse was not killed by the octopus and that the latter merely acted as a scavenger [20]. Hippocampus whitei is endemic to the east coast of Australia [21] and is considered to be Endangered (EN) by the IUCN Red List [4].
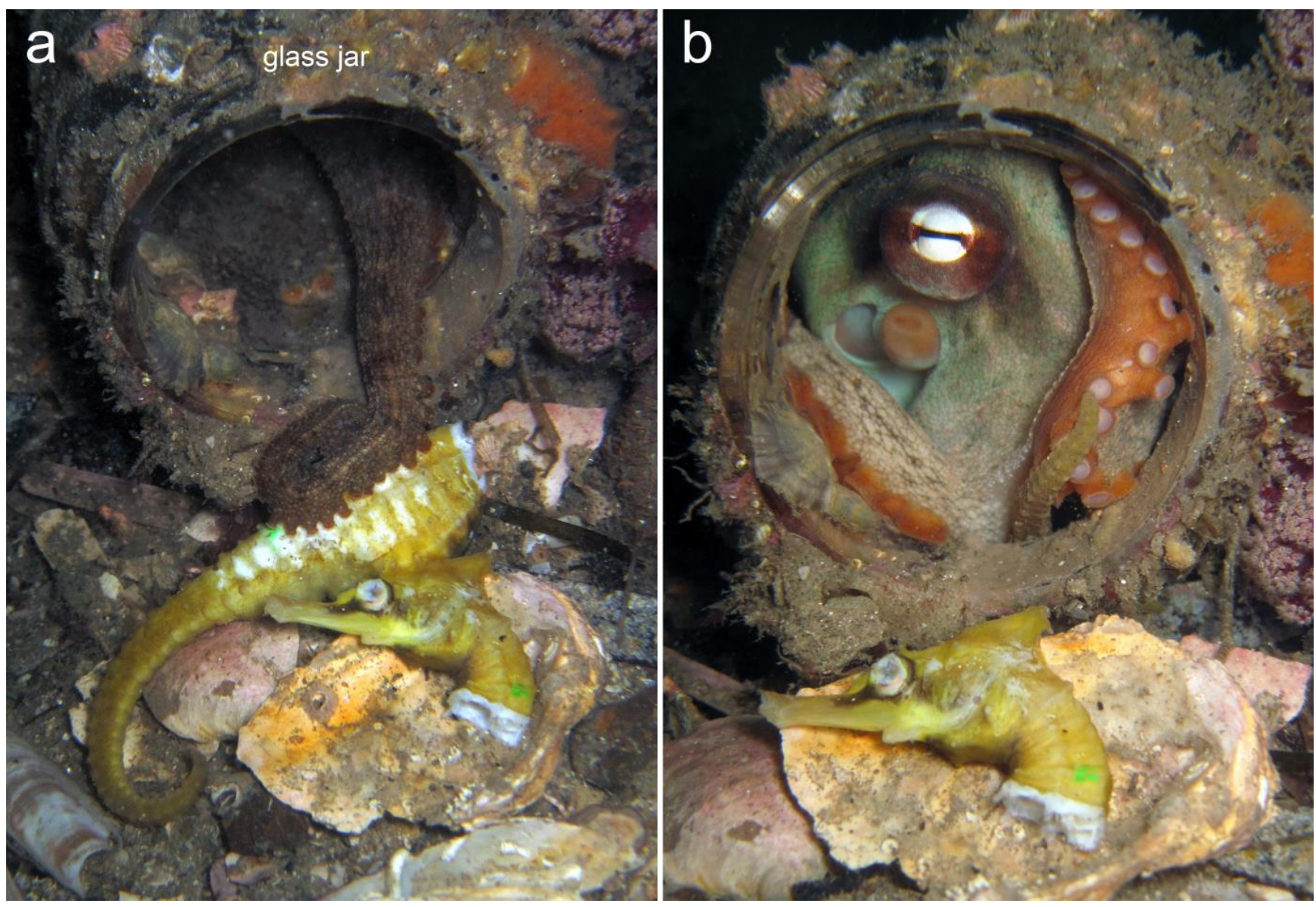

Figure 2. An individual of Hippocampus whitei bitten and partly consumed by a common Sydney octopus (Octopus tetricus) at Port Stephens (NSW, Australia). The octopus is hiding inside a discarded glass jar. (a) Separate head and tail parts of the seahorse in front of the jar. (b) The tail part has disappeared. Green spots: elastomer tag dating from 2007. Photo credit: David Harasti.

The third example is from the same area and the same research project as the former. It is about an individual of $H$. whitei that was caught by a blue-lined octopus, Hapalochlaena fasciata (Figure 3), also at the Pipeline dive site in 2007. The octopus reached out and grabbed the seahorse with a tentacle around the seahorse's neck region. As the octopus started to pull the seahorse towards it, the author intervened and took the seahorse away from the octopus.

Seahorses are probably a less common prey of octopuses than molluscs and crustaceans, which may explain why this has received little attention in the scientific literature. Considering the eight arms, large eyes, complex brain, sharp beak, a tongue with teeth (radula), and venomous bite of octopuses [18], seahorses are doubtless easy prey for them, despite their camouflage and body armour. It is interesting, though, that the seahorses of the first two examples (Figures 1 and 2) had been observed several months prior to their capture, which implies that they had either been overlooked (due to their camouflage) or 
been ignored because they are among the least favourite prey of octopuses. Follow-up research may require an experimental approach.

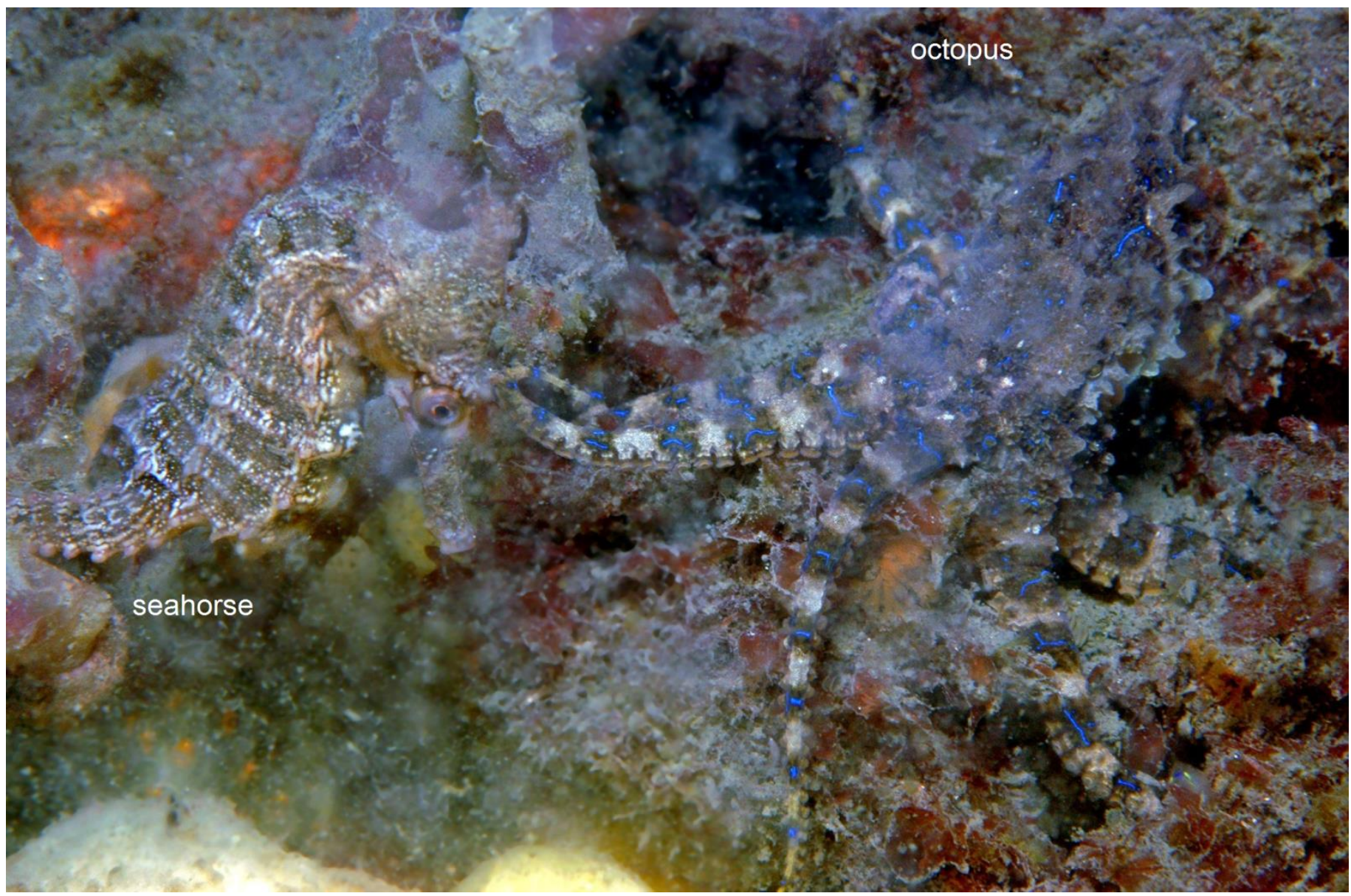

Figure 3. An individual of Hippocampus whitei nearly caught by a blue-lined octopus (Hapalochlaena fasciata) at Port Stephens, NSW, Australia. Both show camouflage. Photo credit: David Harasti.

Supplementary Materials: The following supporting information can be downloaded at: https: / / www.mdpi.com/article/10.3390/d14020125/s1. An individual of Hippocampus whitei caught by a common Sydney octopus (Octopus tetricus) at the Pipeline dive site Port Stephens (NSW, Australia), as in Figure 2.

Author Contributions: Conceptualization, E.M., D.H., B.W.H.; data curation, E.M., D.H.; methodology, E.M., D.H., B.W.H.; investigation, E.M., D.H., B.W.H.; validation, E.M., D.H., B.W.H.; visualization, E.M., D.H.; writing - original draft preparation, B.W.H. writing—review and editing, E.M., D.H., B.W.H. and project administration, B.W.H. All authors have read and agreed to the published version of the manuscript.

Funding: This research received no external funding.

Institutional Review Board Statement: Not applicable.

Data Availability Statement: Data sharing not applicable.

Acknowledgments: We want to thank four anonymous reviewers for their constructive comments, which helped us to improve the manuscript.

Conflicts of Interest: The authors declare no conflict of interest. 


\section{References}

1. Evanson, M.; Foster, S.J.; Wisedel, S.; Vincent, A.C.J. Tracking the International Trade of Seahorses (Hippocampus Species); Fisheries Centre Research Reports 19; University of British Columbia: Vancouver, BC, Canada, 2011; p. 94.

2. Rosa, I.L.; Defavari, G.R.; Alves, R.R.N.; Oliveira, T.P.R. Seahorses in traditional medicines: A global overview. In Animals in Traditional Folk Medicine; Alves, R.R.N., Rosa, I.L., Eds.; Springer: Berlin, Germany, 2013; pp. 207-240. [CrossRef]

3. Chen, L.; Wang, X.; Huang, B. The genus Hippocampus-A review on traditional medicinal uses, chemical constituents and pharmacological properties. J. Ethnopharmacol. 2015, 162, 104-111. [CrossRef] [PubMed]

4. Koning, S.; Hoeksema, B.W. Diversity of seahorse species (Hippocampus spp.) in the international aquarium trade. Diversity 2021, 13, 187. [CrossRef]

5. Foster, S.J.; Kuo, T.C.; Wan, A.K.Y.; Vincent, A.C.J. Global seahorse trade defies export bans under CITES action and national legislation. Mar. Policy 2019, 103, 33-41. [CrossRef]

6. Foster, S.J.; Vincent, A.C.J. Holding governments accountable for their commitments: CITES review of significant trade for a very high-volume taxon. Glob. Ecol. Conserv. 2021, 27, e01572. [CrossRef]

7. Kleiber, D.; Blight, L.K.; Caldwell, I.R.; Vincent, A.C.J. The importance of seahorses and pipefishes in the diet of marine animals. Rev. Fish Biol. Fish. 2011, 21, 205-223. [CrossRef]

8. Harasti, D.; Martin-Smith, K.; Gladstone, W. Does a no-take marine protected area benefit seahorses? PLoS ONE 2014, 9, e105462. [CrossRef]

9. Ternes, M.L.F.; Gerhardinger, L.C.; Schiavetti, A. Seahorses in focus: Local ecological knowledge of seahorse-watching operators in a tropical estuary. J. Ethnobiol. Ethnomed. 2016, 12, 1-12. [CrossRef]

10. Mastrangelli, A.; Silveira, R.B.; Burato, M.; Baldassin, P.; Werneck, M.R. First report of Lepidochelys olivacea feeding on Hippocampus patagonicus in Brazil. Mar. Turtle Newsl. 2019, 159, 26-27.

11. Silveira, R.B.; Silva, J.D.S. Presence of the seahorse Hippocampus reidi (Pisces: Syngnathidae) in diet of marine fish in Northeastern Brazil. Oceanogr. Fish. Open Access J. 2020, 12, 5557830. [CrossRef]

12. Lourie, S.A.; Pritchard, J.C.; Casey, S.P.; Ky, T.S.; Hall, H.J.; Vincent, A.C.J. The taxonomy of Vietnam's exploited seahorses (family Syngnathidae). Biol. J. Linn. Soc. 1999, 66, 231-256. [CrossRef]

13. Foster, S.J.; Vincent, A.C.J. Life history and ecology of seahorses: Implications for conservation and management. J. Fish Biol. 2004, 65, 1-61. [CrossRef]

14. Ambrose, R.F.; Nelson, B.V. Predation by Octopus vulgaris in the Mediterranean. Mar. Ecol. 1983, 4, 251-261. [CrossRef]

15. Bennice, C.O.; Brooks, W.R.; Hanlon, R.T. Behavioral dynamics provide insight into resource exploitation and habitat coexistence of two octopus species in a shallow Florida lagoon. J. Exp. Mar. Biol. Ecol. 2021, 542-543, 151592. [CrossRef]

16. Taylor, P.B.; Chen, L.C. The predator-prey relationship between the octopus (Octopus bimaculatus) and the California scorpionfish (Scorpaena guttata). Pac. Sci. 1969, 23, 311-316.

17. Crocetta, F.; Shokouros-Oskarsson, M.; Doumpas, N.; Giovos, I.; Kalogirou, S.; Langeneck, J.; Tanduo, V.; Tiralongo, F.; Virgili, R.; Kleitou, P. Protect the natives to combat the aliens: Could Octopus vulgaris Cuvier, 1797 be a natural agent for the control of the lionfish invasion in the Mediterranean Sea? J. Mar. Sci. Eng. 2021, 9, 308. [CrossRef]

18. Villanueva, R.; Perricone, V.; Fiorito, G. Cephalopods as predators: A short journey among behavioral flexibilities, adaptions, and feeding habits. Front. Physiol. 2017, 8, 598. [CrossRef] [PubMed]

19. O'Brien, C.E.; Bennice, C.O.; Leite, T. A field guide to distinguishing Octopus insularis and Octopus americanus (Octopoda: Octopodidae). Zootaxa 2021, 5060, 589-594. [CrossRef] [PubMed]

20. Sauer, W.H.H.; Gleadall, I.G.; Downey-Breedt, N.; Doubleday, Z.; Gillespie, G.; Haimovici, M.; Ibáñez, C.M.; Katugin, O.N.; Leporati, S.; Lipinski, M.R.; et al. World octopus fisheries. Rev. Fish. Sci. Aquac. 2021, 29, 279-429. [CrossRef]

21. Short, G.; Harasti, D.; Hamilton, H. Hippocampus whitei Bleeker, 1855, a senior synonym of the southern Queensland seahorse H. procerus Kuiter, 2001: Molecular and morphological evidence (Teleostei, Syngnathidae). ZooKeys 2019, 824, 109-133. [CrossRef] [PubMed] 